\title{
Two new species of the Pterostichus macrogenys species group (Coleoptera, Carabidae) discovered in shallow subterranean habitats in northern Honshu, Japan
}

\author{
Kôji Sasakawa', Hirotarô Itô \\ I Laboratory of Zoology, Department of Science Education, Faculty of Education, Chiba University, 1-33 Yayoi- \\ cho, Inage-ku, Chiba-shi, Chiba, 263-8522 Japan 2 1-14-16 Awayama, Niigata-shi, Niigata, 950-0843 Japan \\ Corresponding author: Kôji Sasakawa (ksasa@chiba-u.jp) \\ Academic editor: O.Moldovan | Received 11 November 2016 | Accepted 16 December 2016 | Published 24 January 2017 \\ http://zoobank.org/E6640ED3-6770-47C8-88AF-BA8C4556C4EA \\ Citation: Sasakawa K, Itô H (2017) Two new species of the Pterostichus macrogenys species group (Coleoptera, Carabidae) \\ discovered in shallow subterranean habitats in northern Honshu, Japan. Subterranean Biology 21: 47-56. https://doi. \\ org/10.3897/subtbiol.21.11155
}

\begin{abstract}
Shallow subterranean environments have recently received attention as a habitat for Carabidae beetles, and many new species have been discovered using collection techniques devised for this habitat. We report the discovery of two new species of the macrogenys species group of the Pterostichus subgenus Nialoe Tanaka, 1958, collected by subterranean baited traps in northern Honshu, Japan. Pterostichus shinbodakensis Sasakawa \& Itô, sp. n. is described from Mt. Shinbodake, Niigata Prefecture, and P. tateishiyamanus Sasakawa \& Itô, sp. n. is described from the southeastern foot of Mt. Tateishiyama, Fukushima Prefecture. Comparative male genital morphology shows that among the known species, the two new species are most closely related to $P$. falcispinus Sasakawa, 2005 and $P$. chokaisanus Sasakawa, 2009, respectively. In addition, sympatric occurrence of $P$. shinbodakensis with a smaller, unidentified species of the species group was also confirmed. The implications of these results for future studies of the macrogenys species group, as well as those of Nialoe, are discussed.
\end{abstract}

\section{Keywords}

Endophallus, ground beetle, male genitalia, Nialoe, Pterostichus shinbodakensis sp. n., Pterostichus tateishiyamanus sp. n., subterranean baited trap, sympatric occurrence, taxonomy

Copyright Kôji Sasakawa, Hirotarô ltô. This is an open access article distributed under the terms of the Creative Commons Attribution License (CC BY 4.0), which permits unrestricted use, distribution, and reproduction in any medium, provided the original author and source are credited. 


\section{Introduction}

The taxonomy of the beetle family Carabidae has been investigated extensively in Japan, with many new species currently being described. Most of these new species are categorized into one of two types. In the first type, the focal species was originally recognized as a single species, but examinations of new characters have revealed that the taxon is actually composed of multiple species, including new species (e.g., Sasakawa 2006, 2009a; Morita 2007). In the second type, completely unknown species have been discovered and described as new taxa (e.g., Kasahara 1991; Imura 2004; Morita et al. 2008).

In the carabid genus Pterostichus Bonelli, 1810 of Japan, most studies during the last decade have described species of the first type (e.g., Sasakawa 2009b, 2009c; Sasakawa and Kubota 2006; Morita 2007, 2010). However, several studies have described species of the second type, and some of these studies provide insight for future studies of Pterostichus in Japan. Specifically, Ito (2010) and Ito and Ogai (2015) described 17 new and one new subterranean species, respectively. They collected specimens of these new species using a new type of baited trap modified for subterranean environments, which to date have received little attention as a habitat for Pterostichus in Japan (Ito 2010; Ito and Ogai 2015; see also Yoshida 2012; Ito 2015). Their discovery of undescribed species indicates a need for future surveys of the habitat in other areas (Yoshida 2012).

We describe two new species of the macrogenys species group of Pterostichus subgenus Nialoe Tanaka, 1958, which we collected from Niigata and Fukushima prefectures, northern Honshu, using subterranean baited traps. The macrogenys species group exhibits marked differentiation in central and northern Honshu, and many species with limited distributions occur there (Sasakawa 2009b). However, there are many localities in which no specimens have been examined, and this limitation has hampered our knowledge of the group's diversity. Thus, examinations of specimens from additional localities have been expected.

\section{Materials and methods}

Beetles were collected using subterranean baited traps modified from the design used by Yoshida (2012). The traps were composed of two different-sized, covered plastic containers $(20.0 \times 11.0 \times 5.0 \mathrm{~cm}$ and $11.5 \times 8 \times 4 \mathrm{~cm})$. The larger container was filled to a depth of $2 \mathrm{~cm}$ with a mixture of nine parts silkworm pupa powder (attractant) and one part salt (preservative for the attractant). The smaller container was then filled to $75 \mathrm{ml}$ with $10-15 \%$ acetic acid (preservative) (Fig. 1). Acetic acid can preserve specimens in the traps for up to 1 month without serious damage to membranous parts of the genitalia, which are important taxonomic characters of Pterostichus. A $3.0 \times 1.5$ $\mathrm{cm}$ rectangle (Fig. 2) or a shape with a $2.0 \mathrm{~cm}$ diameter was cut from the cover of the larger container to allow entry of attracted beetles. The cover of the smaller container was fixed with stainless steel bolts and nuts, $1-1.5 \mathrm{~cm}$ above the cover of the larger con- 

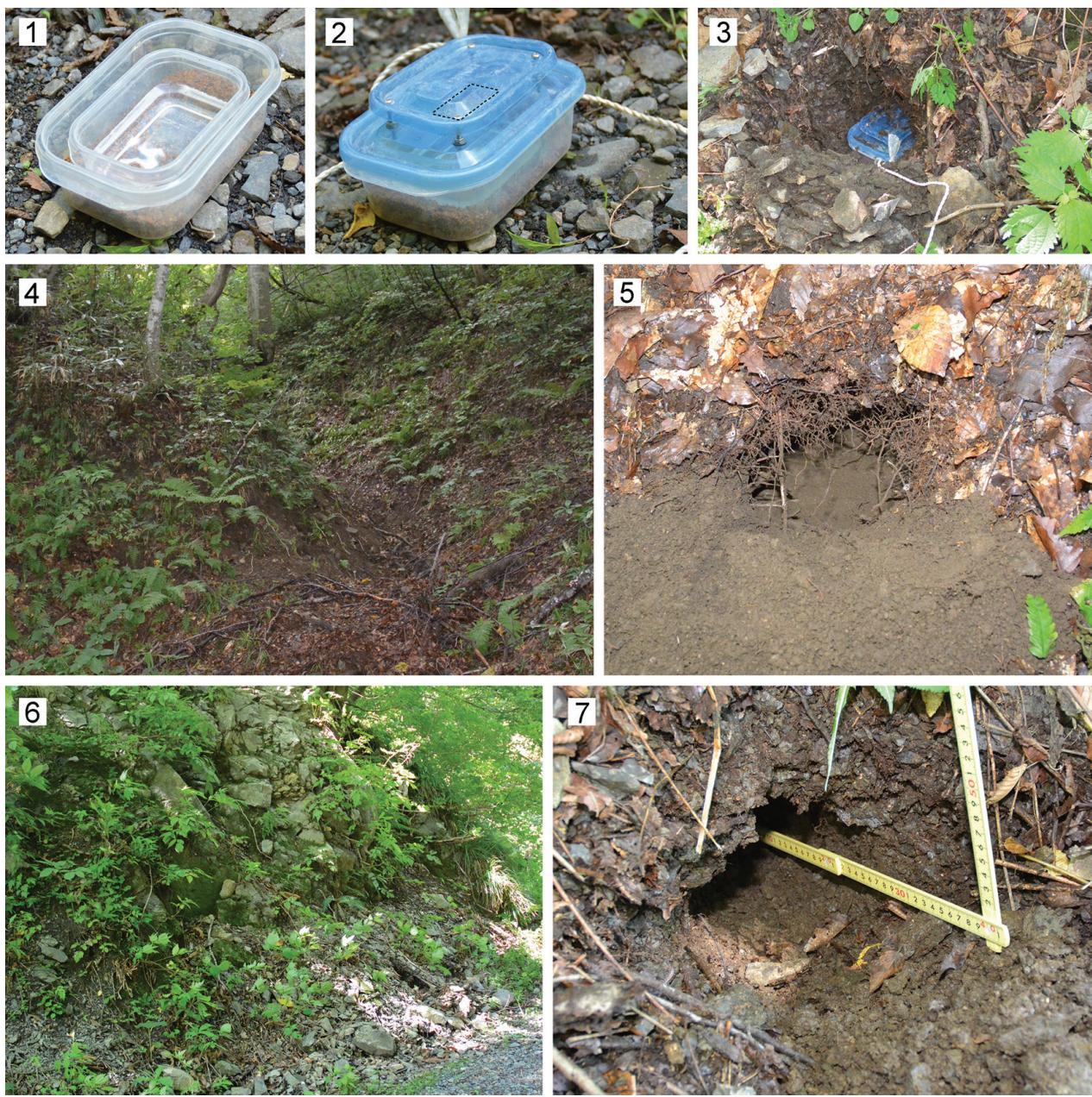

Figures I-7. Design of subterranean baited traps and the aboveground and subterranean environments at the collection sites. I Trap without cover, showing sections containing attractant (larger container) and preservative (smaller container) $\mathbf{2}$ Trap with cover, showing the entrance section (square with broken lines) 3 Trap installed in hole, showing nylon cord, part of which will be left aboveground as a marker 4 Aboveground environment of the Pterostichus shinbodakensis type locality 5 Hole for the trap at the $P$. shinbodakensis type locality, showing the subterranean environment $\mathbf{6}$ Aboveground environment of the $P$. tateishiyamanus type locality $\mathbf{7}$ Hole for the trap at the $P$. tateishiyamanus type locality, showing the subterranean environment. The magnifications of the photos vary (see text for trap size).

tainer; this "roof" prevented soil from entering the trap. A nylon cord was attached to a corner of the cover of the larger container; when the traps were installed belowground, part of the cord was left aboveground as a marker (Fig. 3).

At the Niigata collection site, traps were installed $20 \mathrm{~cm}$ belowground on both sides of slope along a dry watercourse (Figs 4, 5). At the Fukushima collection site, traps were installed 20-40 cm belowground in two colluvial slopes along a road (Figs 6, 7). 
Type materials of the new species have been deposited in the collections of the Laboratory of Forest Zoology, Graduate School of Agricultural and Life Sciences, University of Tokyo, Tokyo, Japan (holotypes) and in those of the authors (paratypes). For comparison, holotypes of P. takadateyamanus Sasakawa, 2009, P. eboshiyamanus Sasakawa, 2009, and P. chokaisanus Sasakawa, 2009 (at the National Museum of Nature and Science, Tokyo, Japan) and a male P. falcispinus Sasakawa, 2005 individual from the type locality (21.v.2013, Hirotarô Itô leg.) were examined. The terminology for the male genitalia follows that of Sasakawa (2009b). Some morphological characters are abbreviated (BLm: body length from mandible apices to elytral end; BLI: body length from anterior margin of labrum to elytral end; BLc: body length from clypeal apex to elytral end; HL: head length from clypeal apex to neck base; HW: head width at widest part; PL: pronotum length along median line; PW: pronotum width at widest part; PAW: pronotal anterior margin width; PPW: pronotal posterior margin width; EL: elytral length from shoulder tip to apices; EW: elytral width at widest part).

\section{Taxonomy}

Pterostichus (Nialoe) shinbodakensis Sasakawa \& Itô, sp. n. http://zoobank.org/02ED4CC6-0F43-4AAC-A86C-771BC0F8DF78 Figs 8, 12-18

Type material. Holotype, ô, Mt. Shinbodake, alt. 540 m, Murakami-shi, Niigata Prefecture, Japan (38.355444 N, 139.516222 E), 6-27.ix.2015, Hirotarô Itô leg.

Etymology. Derived from the name of the type locality.

Diagnosis. Similar to P. takadateyamanus and P. falcispinus but distinguished by the shape of right paramere (Figs 16-20; Sasakawa 2009b, Fig. 20) and distinctly sclerotized left pigmented band (in P. takadateyamanus and P. falcispinus, only slightly sclerotized). Readily distinguished from sympatrically occurring unidentified species (Fig. 9) by a larger body size and smaller eyes (see Remarks).

Measurements. BLm: 16.7 mm; BLl: 14.9 mm; BLc: 14.3 mm; HL/HW: 0.89; PL/PW: 0.64; PAW/PW: 0.89; PPW/PW: 0.77; EL/EW: 1.55.

Description. Head and pronotum dark brown to blackish; elytra reddish-brown; appendages reddish to dark brown. Dorsal surface almost smooth except for laterobasal impressions of the pronotum, which are slightly punctate.

Head large, widest at tempora, which are markedly swollen; width at the widest point larger than pronotal posterior margin width; length from clypeal apex to neck base longer than pronotum length along the median line. Left mandible large and strongly hooked at the apical 1/3; length between mandible apex and posterolateral end on dorsal side over 2.5-fold longer than the anterior width of the clypeus. Eyes small and barely convex, with anterior-posterior length shorter than $1 / 2$ length of the antennal segment 1 . Antennal segment 2 with two setae. 

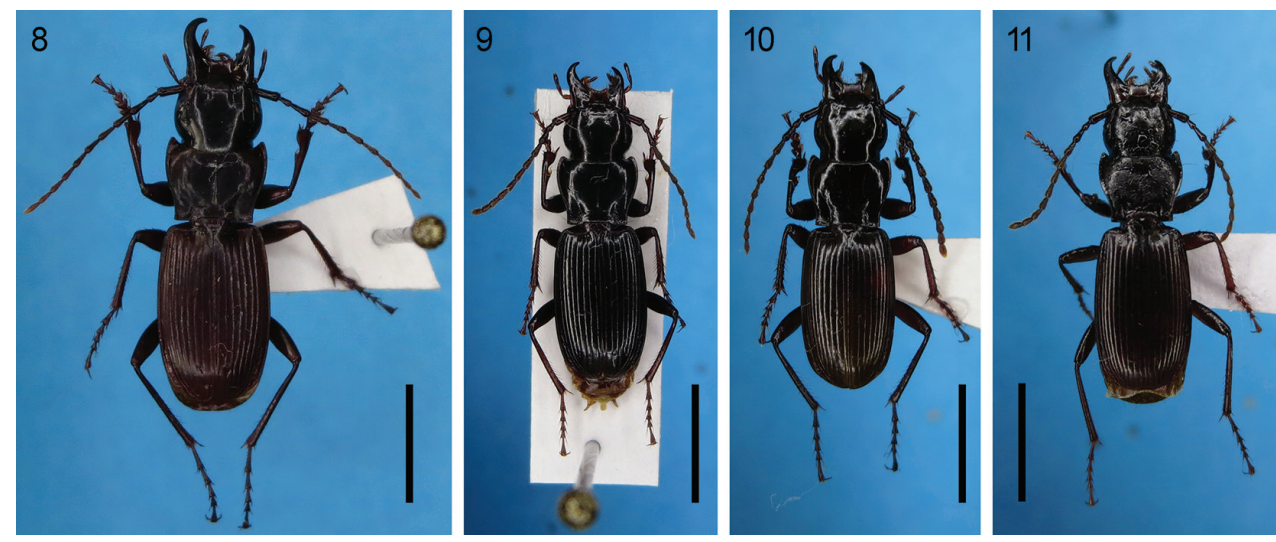

Figures 8-I I. Dorsal view of species of the macrogenys species group. 8 Pterostichus shinbodakensis sp. n., holotype male 9 A female of the unidentified species sympatric with P. shinbodakensis 10 P. tateishiyamanus sp. n., holotype male II P. tateishiyamanus sp. n., paratype female. All figures are of the same magnification. Scale bar $=5.0 \mathrm{~mm}$.

Pronotum cordate, notably flat, widest at apical $1 / 5$. Lateral margins arcuate on apical $2 / 3$, slightly sinuate on basal $1 / 3$; two marginal setae on each lateral side, anterior setae near widest pronotal point, and posterior setae near hind angles. Anterior margin emarginated, with contour arched more strongly than the curvature of apical $2 / 3$ of lateral margins; anterior angles notably produced. Posterior margin emarginated at median area, almost straight at lateral areas; hind angles right-angled. Median line impressed in the middle, not reaching both the anterior and posterior margins; laterobasal impressions single, shallow.

Elytra almost parallel-sided, less convex; shoulder distinct, but not denticulate; apices rounded; scutellar stria present, not connected to stria 1; 1 setigerous puncture on stria 1 at the level of the posterior end of scutellum; two setigerous punctures on interval 3, anterior one slightly behind the middle and posterior one on apical 1/6, both adjoining stria 2 . Hind wings completely atrophied. Male sternum 7 fairly concave.

Aedeagus stout, without tubercle. Endophallus short, stout, strongly bent ventrally, with gonopore directed backward; left pigmented band distinctly sclerotized; right preapical lobe stout, as long as left preapical lobe, with apical part bent toward gonopore; left preapical lobe short, stout, directed toward leftward, with apex narrowly rounded; left apical lobe small but stout, strongly bent backward, with surface distinctly sclerotized. Left paramere square. Right paramere bent at approximately $120^{\circ}$ at apical 2/5; apical part from dorsal view almost flat, with large, widely rounded right corner; ventral side strongly concave.

Remarks. This species is considered most closely related to $P$. falcispinus, because the angle bending (Fig. 17) and the wide apical part (Fig. 16) of the right paramere and the strongly-bent, distinctly sclerotized left preapical lobe (Figs 12-14) are found in only these species among the known Nialoe species (i.e., putative synapomorphies). In other consubgeneric species, the right paramere is short, straight with a rounded apical 
part or slender, arcuate with a narrow apical part (i.e., not bent at an angle and not with a flat apical part), and the left preapical lobe is not distinctly sclerotized.

Although a female of the macrogenys species was also obtained at the type locality (8-30.viii.2015, Hirotarô Itô leg.; Fig. 9), it differs from P. shinbodakensis in several ways: a smaller body size (BLm: $14.0 \mathrm{~mm}$; BLl: $12.7 \mathrm{~mm}$; BLc: $12.2 \mathrm{~mm}$ ), a left mandible that is not elongated (length between mandible apex and posterolateral end on dorsal side is -2.2 -fold as long as the anterior width of the clypeus), smaller eyes (anterior-posterior length is longer than one-half the length of the antennal segment 1), and blackish elytra. Considering the characters of the other species in the group (Figs 10, 11; Sasakawa 2005, 2009b) and direct (Ito and Ogai 2015) and indirect (Sasakawa 2009b) evidence for sympatric occurrence of large and small species in some localities, the focal morphological differences would be between large (P. shinbodakensis) and small species (the focal female), rather than between sexes within the same species. To determine its taxonomic status, male specimens need to be investigated.

\section{Pterostichus (Nialoe) tateishiyamanus Sasakawa \& Itô, sp. n.}

http://zoobank.org/30B86A6D-14E6-461C-B5D9-F970446A3052

Figs 10, 11, 21, 22

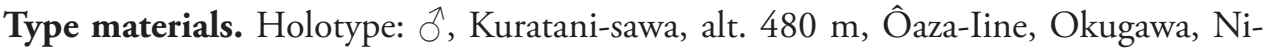
shiaizu-machi, Yama-gun, Fukushima Prefecture, Japan (37.752944 N, 139.683889 E), 18.v-9.vi.2014, Hirotarô Itô leg. Paratypes: $1 \hat{\jmath}$, same data as holotype; 1 q , same locality, but alt. 500 m, 1-14.xi.2015, Hirotarô Itô leg.

Etymology. Derived from Mt. Tateishiyama, on the southeastern foot where the type locality is situated.

Diagnosis. Externally similar to other small-sized species of the macrogenys species group but readily distinguished by the bifurcated distal end of the left preapical lobe.

Measurements. [holotype $\hat{\delta}$ /paratype $\hat{\delta} /$ paratype 9 ] BLm: 14.7/13.6/14.6 mm; BLl: 13.5/12.6/13.4 mm; BLc: 12.9/12.2/12.8 mm; HL/HW: 0.95/0.83/0.86; PL/ PW: 0.71/0.70/0.71; PAW/PW: 0.87/0.86/0.86; PPW/PW: 0.77/0.71/0.72; EL/EW: $1.71 / 1.78 / 1.68$.

Description. Head, pronotum, and elytra dark brown to blackish; appendages dark brown. Dorsal surface almost smooth except for laterobasal impressions of the pronotum, which are slightly punctate.

Head large, widest at tempora, which are distinctly swollen; width at the widest point larger than pronotal posterior margin width; length from clypeal apex to neck base larger than pronotum length along the median line. Left mandible large and curved at the apical 1/4; length between mandible apex and posterolateral end on dorsal side -2.2 -fold as long as the anterior width of the clypeus. Eyes weakly convex, with the anterior-posterior length longer than $1 / 2$ length of antennal segment 1 . Antennal segment 2 with two setae. 

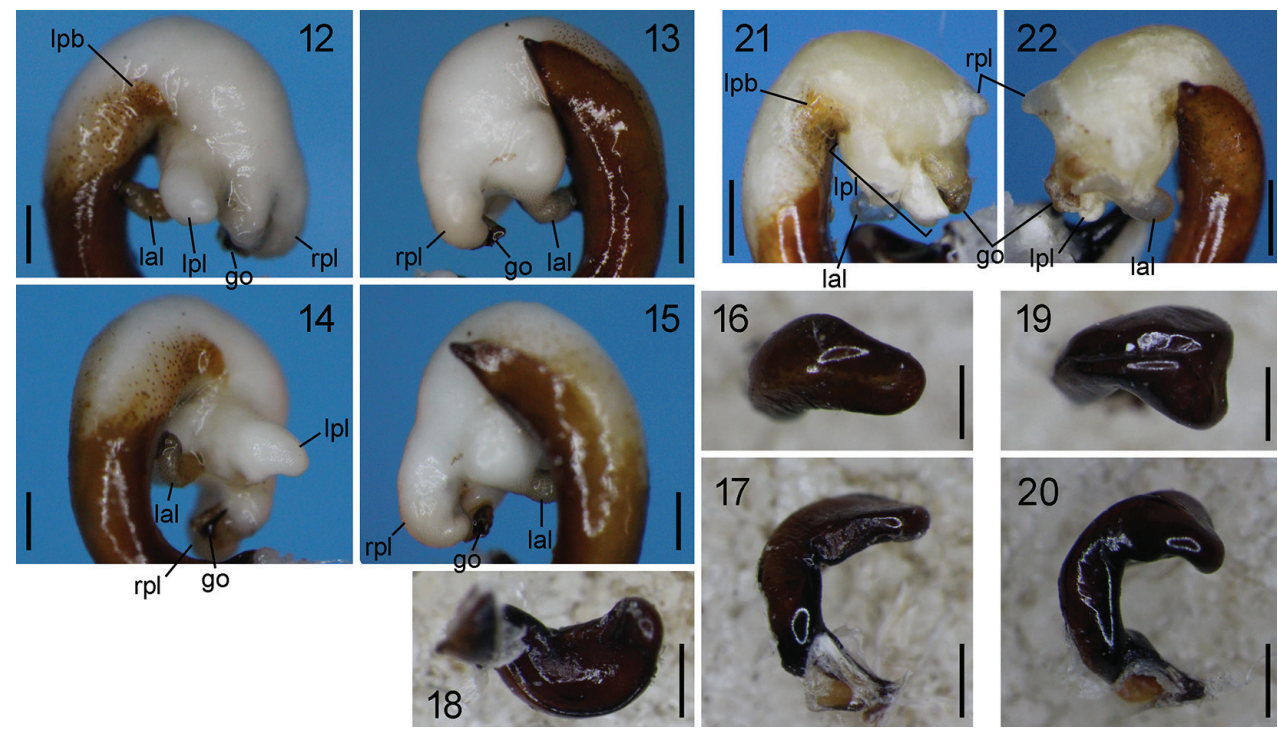

$\mathrm{rpl}^{\prime} \mathrm{go}$

Figures 12-22. Male genitalia of species of the macrogenys species group. Left lateral view (I2), right lateral view (13), left dorsolateral view (14), and right dorsolateral view (I5) of endophallus of $P$. shinbodakensis sp. n., holotype. Dorsal view of apical part (I6), left lateral view (I7), and ventral view of apical part (18) of right paramete of $P$. shinbodakensis sp. n., holotype. Dorsal view of apical part (19) and left lateral view (20) of right paramete of $P$. falcispinus from the type locality. Left lateral view (2I) and right lateral view (22) of endophallus of $P$. tateishiyamanus sp. n., holotype. go: gonopore; lal: left apical lobe; lpb: left pigmented band; lpl: left preapical lobe; rpl: right preapical lobe. Scale bar $=0.5 \mathrm{~mm}$.

Pronotum cordate, notably flat, widest at apical $1 / 5$. Lateral margins arcuate on apical $2 / 3$, slightly sinuate on basal $1 / 3$; two marginal setae on each lateral side, anterior setae near widest pronotal point and posterior setae near hind angles. Anterior margin emarginated, with curvature approximately the same as that of apical $2 / 3$ of lateral margins; anterior angles notably pronounced in the female, less pronounced in the male. Posterior margin emarginated at median area, almost straight at lateral areas; hind angles right-angled. Median line impressed in the middle, reaching the posterior margin in the holotype male but not reaching both anterior and posterior margins in the paratype male and female; laterobasal impressions single, shallow.

Elytra almost parallel-sided, less convex; shoulder distinct, but not denticulate; apices rounded; scutellar stria present, connected to stria 1 in the male specimens; in the paratype female, stria 1 disconnected at the level of the posterior end of the scutellar stria, where only the scutellar stria is connected to the other part of stria 1; one setigerous puncture on stria 1 at the level of the posterior end of the scutellum; two setigerous punctures on interval 3, anterior one slightly behind the middle and posterior one on apical $1 / 5-1 / 4$, both adjoining stria 2 . Hind wings completely atrophied. Male sternum 7 slightly concave. Female first fore tarsomere without adhesive hairs on ventral side. 
Aedeagus stout without tubercle. Endophallus short, stout, strongly bent ventrally, with gonopore directed backward; left pigmented band weakly sclerotized; right preapical lobe small; left preapical lobe large, with bifurcated distal end; left apical lobe bifurcated, with slender and narrowly rounded apices. Left paramere square. Right paramere short, straight, rounded apically.

Remarks. Among the known members of the macrogenys species group, this species is considered the most closely related to P. chokaisanus, because the two species have slender and narrowly rounded bifurcated apices of the left apical lobe; this character is found only in these species among the species group and thus is an apomorphic character state.

\section{Discussion}

As noted in the Taxonomy section, this study provides some insights into the current understanding of the macrogenys species group. In particular, that two differentsized species occur sympatrically at the $P$. shinbodakensis type locality is notable; this is because although sympatric occurrence provides definitive evidence for reproductive isolation between species and thereby their distinct species status, in the macrogenys species group, such sympatry has been confirmed for only one pair of species (Ito and Ogai 2015). Importantly, in both that study and ours, sympatry was confirmed by subterranean baited traps, which can remain installed for a long period, typically over several weeks. On the other hand, no report has confirmed sympatric occurrence of members of the macrogenys species group using conventional baited pitfall traps, which are placed aboveground for one or a few nights, despite their widespread use. Collection of these species using short-term traps is probably difficult due to their rarity. Thus, our results, together with previous reports, show that subterranean baited traps are effective not only for the discovery of new species but also for studying the relationships among known species.

Our results are also notable with respect to the collection sites. In other carabid groups that include subterranean species, the relative importance of subterranean and aboveground habitats differs among regions. For example, in the Platynini genus $J u$ jiroa, species of the Tôkai and Kinki districts of Honshu and Shikoku occur exclusively in subterranean environments, while those in other areas occur in aboveground habitats (e.g., Habu 1978; Sasakawa 2006; Sasakawa and Toki 2008). In the subgenus Nialoe, which includes the macrogenys species group, species occurring in shallow subterranean habitats have been reported in Shikoku and central Honshu (e.g., Kasahara and Itô 1987; Ito 2010; Ito and Ogai 2015) but not in other regions. The discovery of our species in northern Honshu, together with the fact that field surveys using subterranean traps have not been performed in most areas of Japan, shows that shallow subterranean environments may serve as a habitat for this subgenus over a larger area than was recognized previously. 


\section{Acknowledgements}

This study was partly supported by a grant-in-aid from the Japan Society for the Promotion of Science (no. 25830150).

\section{References}

Habu A (1978) Fauna Japonica. Carabidae: Platynini (Insecta: Coleoptera). Keigaku Publishing, Tokyo, $447 \mathrm{pp}$.

Imura Y (2004) Discovery of Hemicarabus macleayi (Coleoptera, Carabidae) from the alpine zone of the Island of Rishiri-to, northeast Japan. Elytra 32: 235-240.

Ito N (2010) Systematics of Pterostichus yoshidai and its relatives (Coleoptera: Carabidae : Pterostichini). Entomological Review of Japan 65: 333-374.

Ito N, Ogai T (2015) A new species of macrocephalic carabid from Nagano Prefecture, Japan (Coleoptera: Carabidae: Pterostichini). Japanese Journal of Systematic Entomology 21: 271-275.

Ito Y (2015) The macrocephalic Pterostichus living in the upper hypogean zone of Shikoku, Japan. The Nature and Insects 50: 19-22. [In Japanese]

Kasahara S (1991) Three new carabid beetles from the Ogasawara Islands. Elytra 19: 243-250.

Kasahara, Itô Y (1987) A new Pterostichus (Coleoptera, Carabidae) from the upper hypogean zone of central Shikoku, southwest Japan. Kontyû 55: 139-145.

Morita S (2007) Notes on the Pterostichine subgenus Eosteropus (Coleoptera, Carabidae) from Japan: Part 1. Complex of Pterostichus japonicus. Elytra 35: 407-432.

Morita S (2010) Notes on the Pterostichine Subgenus Eosteropus (Coleoptera, Carabidae) from Japan: Part 4. Eight new species of the creper complex from central Japan. Elytra 38: 105-124.

Morita S, Toda N, Kanie N (2008) A new Paranchodemus (Coleoptera, Carabidae) from Central Japan. Elytra 36: 349-355.

Sasakawa K (2006) Speciation and dispersal process of Jujiroa Uéno, 1952 (Coleoptera, Carabidae) in the Japanese Archipelago, with descriptions of five new species. Biogeography 8: $45-53$.

Sasakawa K (2009a) Five new species of the ground beetle subgenus Sadonebria Ledoux \& Roux, 2005 (Coleoptera, Carabidae, Nebria) from Honshu, Japan. Biogeography 11: 47-51.

Sasakawa K (2009b) Pterostichus macrogenys Bates (Coleoptera: Carabidae) and its allied species of northern Japan: descriptions of seven additional species and possible evidence supporting species status. Zoological Studies 48: 262-269.

Sasakawa K (2009c) Notes on two species of the subgenus Lyrothorax Chaudoir (Coleoptera: Carabidae; genus Pterostichus), Pterostichus amagisanus Tanaka and Ishida and Pterostichus fujitai Tanaka and Ishida. Entomological science 12: 188-193. https://doi.org/10.1111/ j.1479-8298.2009.00323.x

Sasakawa K, Kubota K (2006) Phylogenetic studies of the subgenus Petrophilus Chaudoir (Coleoptera: Carabidae: Pterostichus), with description of a new species sympatric with $P$. thunbergi Morawitz. Zootaxa 1357: 31-43. 
Sasakawa K, Toki W (2008) A new record, sperm bundle morphology and preliminary data on the breeding type of the ground beetle Jujiroa estriata Sasakawa (Coleoptera: Carabidae: Platynini). Entomological Science 11: 415-417. https://doi.org/10.1111/j.14798298.2008.00289.x

Yoshida M (2012) How to collect insects living in upper hypogean by using underground traps. The Nature and Insects 47: 6-12. [In Japanese] 